\title{
Effects of precipitation and potential evaporation on actual evapotranspiration over the Laohahe basin, northern China
}

\author{
Y. Liu, L. Ren, X. Yang, M. Ma, F. Yuan, and S. Jiang \\ State Key Laboratory of Hydrology-Water Resources and Hydraulic Engineering, College of Hydrology and \\ Water Resources, Hohai University, Nanjing 210098, China \\ Correspondence to: L. Ren (njrl19999@126.com)
}

Received: 12 March 2015 - Accepted: 12 March 2015 - Published: 12 June 2015

\begin{abstract}
Problems associated with water scarcity are facing new challenges under the climate change. As one of main consumptions in water cycle on the Earth, evapotranspiration plays a crucial role in regional water budget. In this paper, we employ two methods, i.e. hydrological sensitivity analysis and hydrological model simulation, to investigate the effect of climate variability and climatic change on actual evapotranspiration $\left(E_{\mathrm{a}}\right)$ within the Laohahe basin during 1964-2009. Calibrations of the two methods are firstly conducted during the baseline period (1964-1979), then with the two benchmarked models, simulations in climatic change duration (1980-2009) are further conducted and quantitative assessments on climatic change-induced variation of $E_{\mathrm{a}}$ are analysed accordingly. The results show that affected by combined impacts of decreased precipitation and potential evapotranspiration, variation of annual $E_{\mathrm{a}}$ in most sub-catchments suffer a downward trend during 1980-2009, with a higher descending rate in northern catchments. At decadal scale, $E_{\mathrm{a}}$ shows significant oscillation in accordance with precipitation patterns. Northern catchments generally suffer more decadal $E_{\mathrm{a}}$ changes than southern catchments, implying the impact of climatic change on decadal $E_{\mathrm{a}}$ is more intense in semi-arid areas than that in semi-humid regions. For whole changed durations, a general 0-20 mm reduction of $E_{\mathrm{a}}$ is found in most parts of studied region. For this water-limited region, $E_{\mathrm{a}}$ shows higher sensitivity to precipitation than to potential evaporation, which confirms the significant role of precipitation in controlling $E_{\mathrm{a}}$ patterns, whereas the impact of potential evapotranspiration variation would be negligible.
\end{abstract}

\section{Introduction}

The compelling phenomenon of global warming (IPCC, 2007) has attracted much attention recently. Huntington (2006) pointed out that the most important consequence due to climatic change should be its intensification of hydrological cycle both at regional and global scales. As the main consumption of water resources, evapotranspiration plays an important role in regional water budget, especially for waterdeficit areas. During the past 50 years, a downward trend of pan evaporation and/or reference evapotranspiration has been found in most regions of the world, covering countries both in northern and southern hemispheres (Peterson et al., 1995; Chattopadhyay et al., 1997; Roderick et al., 2004; Liu et al., 2004; Burn et al., 2007).
The decline of pan and reference evaporation indicates accepted reduction in total energy supply, but it is also debatable whether it implies a similar tendency for actual evapotranspiration $\left(E_{\mathrm{a}}\right)$. Liu et al. (2010) analyzed the $E_{\mathrm{a}}$ over the Yellow River basin, and a decreasing trend was detected during 1961-2006. Similar results were obtained in the Hai River basin, China (Li et al., 2013). In this study, the Laohahe basin, located in northern China, is chosen as a case study on $E_{\mathrm{a}}$ modeling and relevant spatio-temporal variations analyzing. To address this, two methods are adopted. One is the hydrological sensitivity analysis (HS) implemented on the basis of Fu's equation (Fu, 1981). The other is the hydrological model simulation (HM) by the Variable Infiltration Capacity (VIC) model. Specific objectives of our study are to calculate and compare annual $E_{\mathrm{a}}$ with two different methods, and 


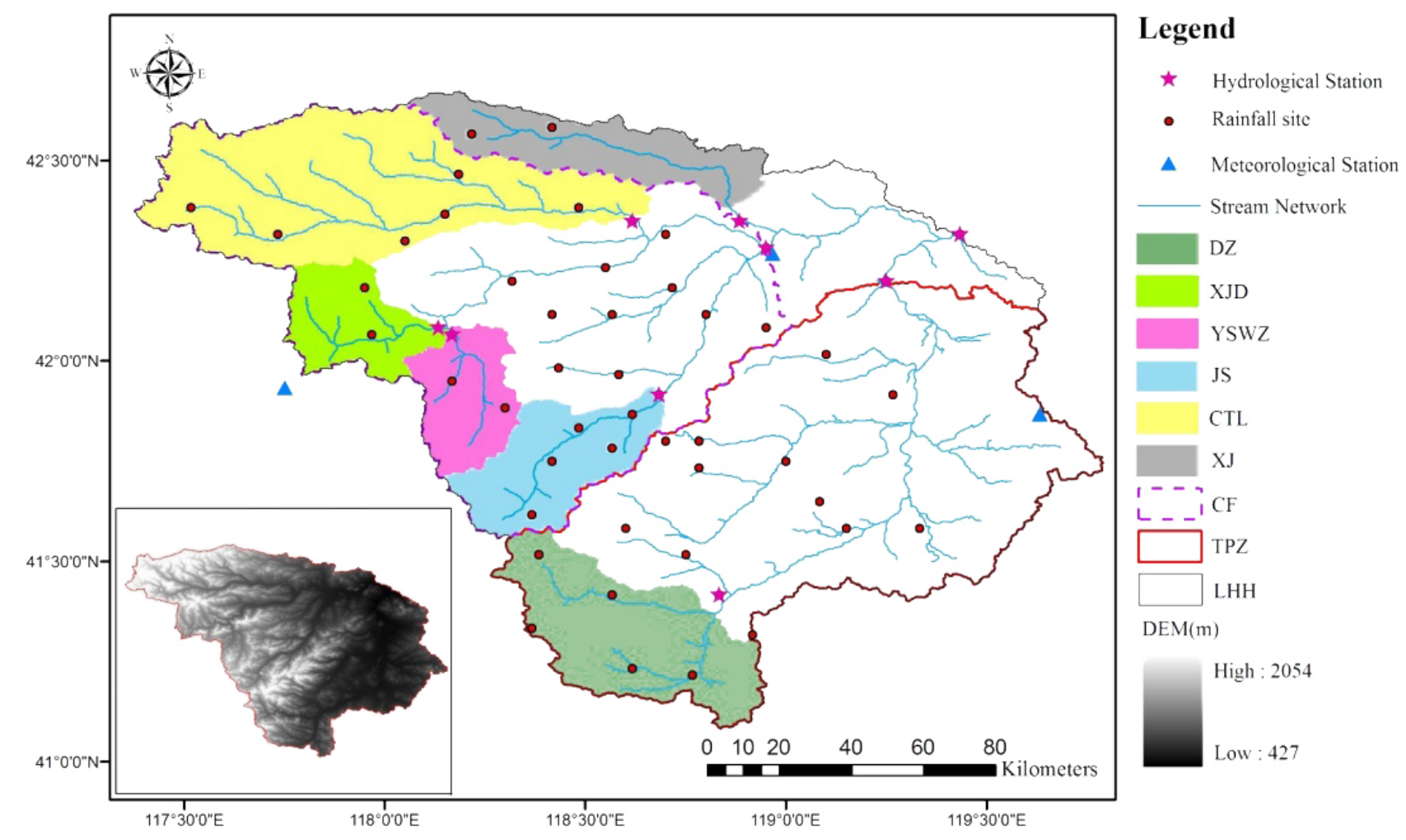

Figure 1. Location of the Laohahe basin (LHH), distribution of hydro-meteorological stations, and watershed divides of 9 sub-catchments with their names.

to comprehensively estimate the impacts of climate variability and climate change on $E_{\mathrm{a}}$ at multiple time scales.

\section{Study area and data}

The Laohahe basin is located at the junction of the Hebei Province, Liaoning Province, and Inner Mongolia Autonomous Region between $41-42.75^{\circ} \mathrm{N}, 117.25-120^{\circ} \mathrm{E}$ (Fig. 1), with $18112 \mathrm{~km}^{2}$ of area. Its elevation ranges from 427 to $2054 \mathrm{~m}$, and significantly descends from southwest to northeast. The mean areal annual temperature, precipitation and runoff during the period of $1964-2009$ are $7.58^{\circ} \mathrm{C}, 418.3$ and $28.7 \mathrm{~mm}$ respectively, and about $80 \%$ of the annual precipitation falls from May to September every year. Besides the whole Laohahe basin, we select other 8 sub-catchments (Fig. 1) including 6 headwater catchments (colored areas) and 2 midstream catchments (marked with red-line boundaries) for analysis.

Observed daily records of 52 precipitation-gauged stations and 9 discharge-measured ones are provided by the Water Resources Department of Inner Mongolia Autonomous Region. Meteorological observations are obtained from four national standardized meteorological stations. All these hydrometeorological variables have continuous records from 1964-2009. The Inverse Distance Weighting method (IDW, Bartier and Keller, 1996) is adopted to generate distributed precipitation and areal values. Potential evaporation (PET) is calculated with the Penman-Monteith equation recommended by the Food and Agriculture Organization (FAO, Allen et al., 1998). In addition, the soil and vegetation data needed by VIC are collected. The soil data are derived from the 5-min the Food and Agriculture Organization dataset, and the land cover data is provided by the Chinese Academy of Science.

\section{Methodology}

\subsection{Hydrological sensitivity analysis}

Hydrological sensitivity analysis is based on the assumption that a variation in mean annual runoff or evapotranspiration can be determined by the following expression (Koster and Suarez, 1999):

$\Delta X=\beta \Delta P+\gamma \Delta \mathrm{PET}$.

where $\Delta X$ represents the change in runoff or evapotranspiration in response to alterations in precipitation and PET; $\beta$ and $\gamma$ are the sensitivity coefficients with respect to precipitation and PET respectively. The sensitivity coefficients are generally derived from evaporation equations by computing partial derivatives with respect to precipitation and PET, re- 
spectively, which can be further expressed as:

$\Delta E=\frac{\partial E}{\partial P} \times \Delta P+\frac{\partial E}{\partial \mathrm{PET}} \times \Delta \mathrm{PET}$.

In this study, the Fu's equation (Fu, 1981) proposed on the basis of the Budyko's hypothesis is employed to estimate average annual evapotranspiration and relevant sensitivity coefficients, whose analytical expression is described as:

$$
\frac{E_{\mathrm{a}}}{P}=1+\frac{\text { PET }}{P}-\left[1+\left(\frac{\mathrm{PET}}{P}\right)^{\varpi}\right]^{1 / \varpi} .
$$

where $\varpi$ is a model parameter determined by land surface conditions including relative infiltration capacity, catchment average slope and fractional vegetation coverage (Yang et al., 2007). Accordingly, sensitivity coefficients (partial derivatives) based on Eq. (3) are given as:

$$
\begin{aligned}
& \frac{\partial E_{\mathrm{a}}}{\partial P}=1-\left[1+\left(\frac{\mathrm{PET}}{P}\right)^{\varpi}\right]^{\frac{1}{\sigma}-1} \\
& \frac{\partial E_{\mathrm{a}}}{\partial \mathrm{PET}}=1-\left[1+\left(\frac{\mathrm{PET}}{P}\right)^{\varpi}\right]^{\frac{1}{\omega}-1}\left(\frac{\mathrm{PET}}{P}\right)^{\varpi-1} .
\end{aligned}
$$

Thus, estimating the impact of climatic change on evapotranspiration can be realized by substituting Eqs. (4) and (5) into Eq. (2). It should also be noted that the parameter $\varpi$ is calibrated by comparing average annual $E_{\mathrm{a}}$ derived from Eq. (3) and from water balance analysis during the baseline period. Relevant performance is evaluated by three statistical indices: the root of mean square error (RMSE), relative bias (BIAS) and correlation coefficient (CC).

\subsection{Hydrological model simulation}

Hydrological model is also a widely used tool for assessing hydrological responses to climate change (Bao et al., 2011; Lan et al., 2013). Different from hydrological sensitivity analysis, it elaborately depicts hydrological processes with physically based framework at flexible time step. In this study, the semi-distributed Variable Infiltration Capacity model (VIC, Liang et al., 2004) is selected, which plays multiple roles, as both a hydrological model and land surface model (LSM). VIC has been extensively used in studies on topics ranging from water resources management to landatmosphere interactions. It balances both the water and surface energy budgets within the grid cell, and accounts for the effects of sub-grid-scale variability in soil, vegetation, precipitation, and topography on grid-scale fluxes. Specifically for its evaporation section, the total actual evapotranspiration over a grid cell is computed as a weighted sum of three types of evaporation including evaporation from the canopy layer of each vegetation tile, transpiration from each of the vegetation tile and evaporation from the bare soil.

Actual evapotranspiration calculated by VIC is mainly controlled by soil and vegetation parameters, and most of them can be obtained from remote sensing data and relevant organizations (Hansen et al., 2000; FAO, 1998) without calibration, except seven parameters $\left(i, d_{1}, d_{2}, d_{3}, D_{\mathrm{s}}, D_{\mathrm{smax}}\right.$ and $W_{\mathrm{s}}$ ) which are subject to calibration based on the agreement between simulated and observed hydrographs (Xie et al., 2006). For model implementation, the VIC model is run at a daily time step with $0.0625^{\circ} \times 0.0625^{\circ}$ of spatial resolution. Calibration is conducted on streamflow by optimizing seven parameters with two criteria: Nash-Sutcliffe Coefficient of Efficiency (NSCE) and BIAS. Table 1 lists the seven optimized parameters and the calibration results for main sub-catchments. It is seen that the NSCEs vary between 0.6 and 0.82 and absolute values of the BIAS range from 0.4 to $6 \%$, indicating that the calibrated VIC model generally capture the natural variability of observed hydrographs.

\section{Results and discussion}

\subsection{Actual evapotranspiration modeling}

Fig. 2 shows the comparison of annual $E_{\mathrm{a}}$ derived from the two models in the baseline period (1964-1979) and change periods (1980-2009), respectively. The best fitted results occur in XJ, CF and LHH catchments with all calculated samples close to the 1:1 line (Fig. 2a, g, i). As regards DZ and TPZ catchments, the $E_{\mathrm{a}}$ series derived from Fu's equation are generally smaller than that from the VIC model (Fig. 2f, h), and opposite patterns are exhibited in YSWZ, JS and CTL catchments (Fig. 2b, d, e). Generally, for all 9 catchments points in the scatter plots are concentrated with the values of RMSE varying between 20.1 and $50.3 \mathrm{~mm}$ and those of CC almost above 0.8 .

\subsection{Multi-scale analysis of $E_{\mathrm{a}}$ changes}

The difference between simulated $E_{\mathrm{a}}$ in the changed periods and baseline periods are further analyzed at multiple time scales (annual, decadal and whole changed durations) to reflect heterogeneous characteristics of $E_{\mathrm{a}}$ changes $(\Delta E)$. At annual scale, simple linear regression is introduced to reflect $\Delta E$ trend during 1980-2009. As can be seen in Fig. 3, most sub-catchments suffer negative trends, and the results are similar to Li et al. (2013) which demonstrated the actual evapotranspiration in Haihe River basin (close to our study area with similar climatic conditions) significantly decreased. On the whole, northern catchments (CTL, XJ and $\mathrm{CF}$ ) within the Laohahe basin have suffered higher descending rates than the southern catchments (YSWZ, JS and TPZ). It implies that tendency of climatic change in semi-arid regions is more significant than in semi-humid areas.

At decadal scale, a decrease-increase-decrease pattern of $\Delta E$ is found in those 9 catchments (Table 2). For the whole studied basin, $\Delta E$ computed by the hydrological model are $-38.6,21.2$ and $-49.6 \mathrm{~mm}$ in $1980 \mathrm{~s}, 1990 \mathrm{~s}$ and $2000 \mathrm{~s}$, respectively, while corresponding values given by the hy- 

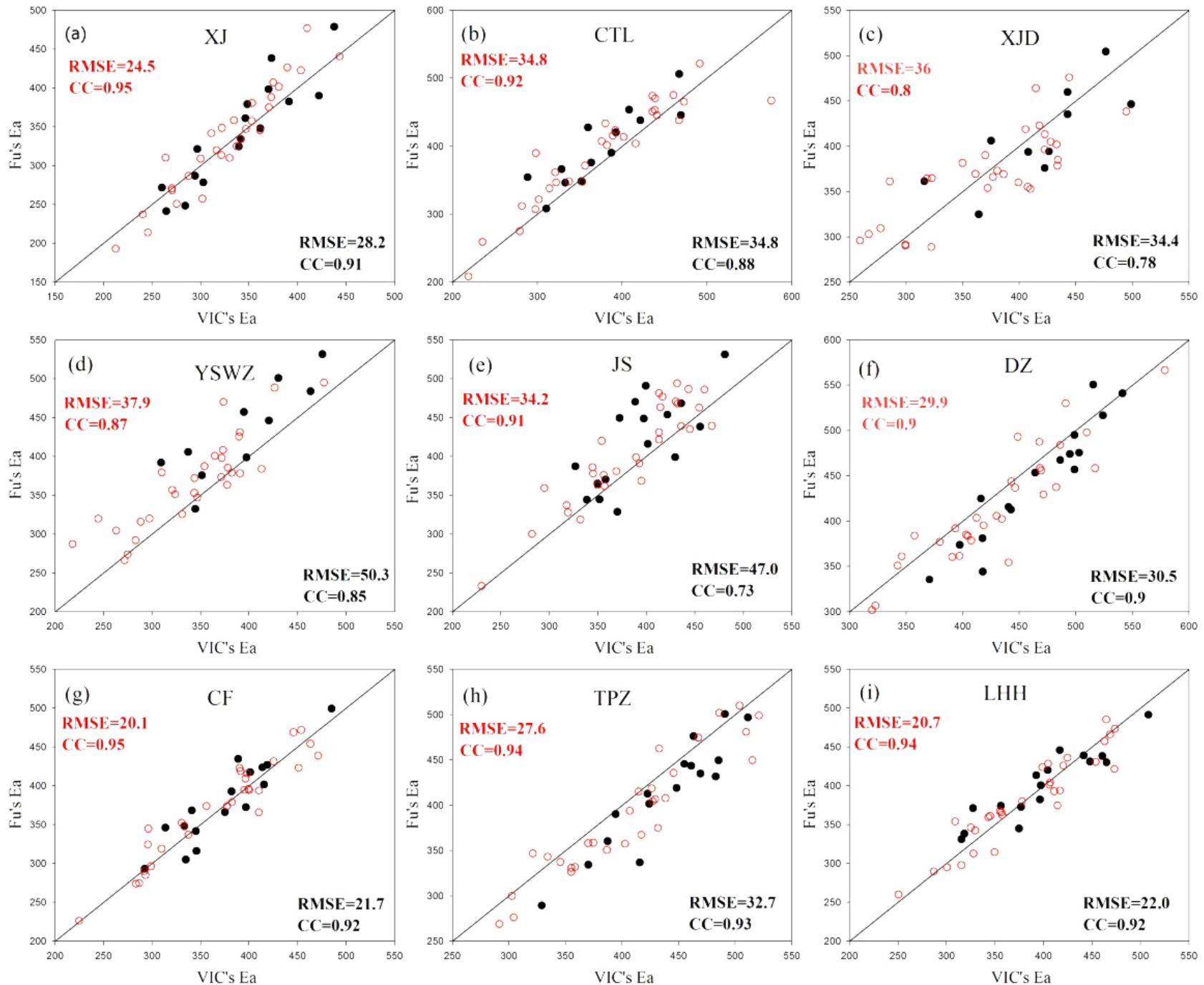

Figure 2. Comparison of annual $E_{\mathrm{a}}$ simulated by VIC-3L model and Fu's equation for (a-i) 9 catchments. The black solid (red hollow) circles represent results in the baseline (subsequent) periods.

Table 1. Optimized parameters and performance of the VIC model during the baseline period.

\begin{tabular}{lrrrrrrrrr}
\hline \multirow{2}{*}{ Catchments } & \multicolumn{9}{c}{ Calibrated parameters } \\
\cline { 2 - 10 } & $i$ & $d_{1}$ & $d_{2}$ & $d_{3}$ & $D_{\mathrm{s}}$ & $D_{\text {smax }}$ & $W_{\mathrm{s}}$ & NSCE & BIAS (\%) \\
\hline XJD & 0.25 & 0.07 & 0.5 & 2 & 0.01 & 6 & 0.98 & 0.72 & 0.9 \\
CTL & 0.26 & 0.07 & 0.62 & 2 & 0.01 & 9 & 0.98 & 0.7 & 0.4 \\
JS & 0.54 & 0.07 & 0.62 & 2 & 0.03 & 8 & 0.98 & 0.6 & -6 \\
DZ & 0.31 & 0.07 & 0.4 & 2 & 0.01 & 6 & 0.98 & 0.8 & 5.6 \\
CF & 0.27 & 0.07 & 0.62 & 2 & 0.01 & 8 & 0.98 & 0.71 & 3.9 \\
TPZ & 0.2 & 0.07 & 0.64 & 2 & 0.006 & 6 & 0.98 & 0.82 & 2.8 \\
LHH & 0.3 & 0.07 & 0.57 & 2 & 0.01 & 9 & 0.98 & 0.81 & 2.1 \\
\hline
\end{tabular}

drological sensitivity analysis method are $-35.8,25$ and $-50 \mathrm{~mm}$, respectively. It is obvious that dry climatic circumstances (1980s and 2000s) have imposed more effect on $E_{\mathrm{a}}$ than the wet status (1990s). For the two midstream catch- ments, TPZ catchment shows more reduction of $E_{\mathrm{a}}$ than CF catchment during dry decade, whereas more increments of $E_{\mathrm{a}}$ are found in CF catchment in the wet decade. It implies that the impact of climatic change on $E_{\mathrm{a}}$ is more intense in 
Table 2. Estimates of $\Delta E\left(\mathrm{~mm} \mathrm{yr}^{-1}\right)$ for 9 catchments derived from hydrological model simulation method (HM) and hydrological sensitivity analysis method (HS) during the changed periods.

\begin{tabular}{lrrrrrr}
\hline \multirow{2}{*}{ Catchments } & \multicolumn{2}{c}{$1980-1989$} & \multicolumn{2}{c}{$1990-1999$} & \multicolumn{2}{c}{$2000-2009$} \\
\cline { 2 - 7 } & HM & HS & HM & HS & HM & HS \\
\hline XJ & -15.3 & -23.1 & 39.5 & 25.4 & -50.5 & -49.7 \\
CTL & -14.9 & -0.9 & 48.6 & 49.2 & -42.1 & -36.8 \\
XJD & -51.8 & -64.2 & 19.0 & 18.0 & -39.4 & -29.6 \\
YSWZ & -63.0 & -49.8 & -0.1 & 12.3 & -67.7 & -48.3 \\
JS & -33.5 & -24.9 & 27.2 & 26.2 & -35.5 & -28.4 \\
DZ & -52.7 & -50.1 & 11.0 & -0.6 & -44.8 & -56.7 \\
CF & -25.7 & -24.2 & 40.8 & 38.0 & -40.3 & -36.5 \\
TPZ & -45.5 & -51.1 & 27.2 & 15.6 & -47.3 & -56.3 \\
LHH & -38.6 & -36.3 & 21.2 & 24.3 & -49.6 & -51.2 \\
\hline
\end{tabular}
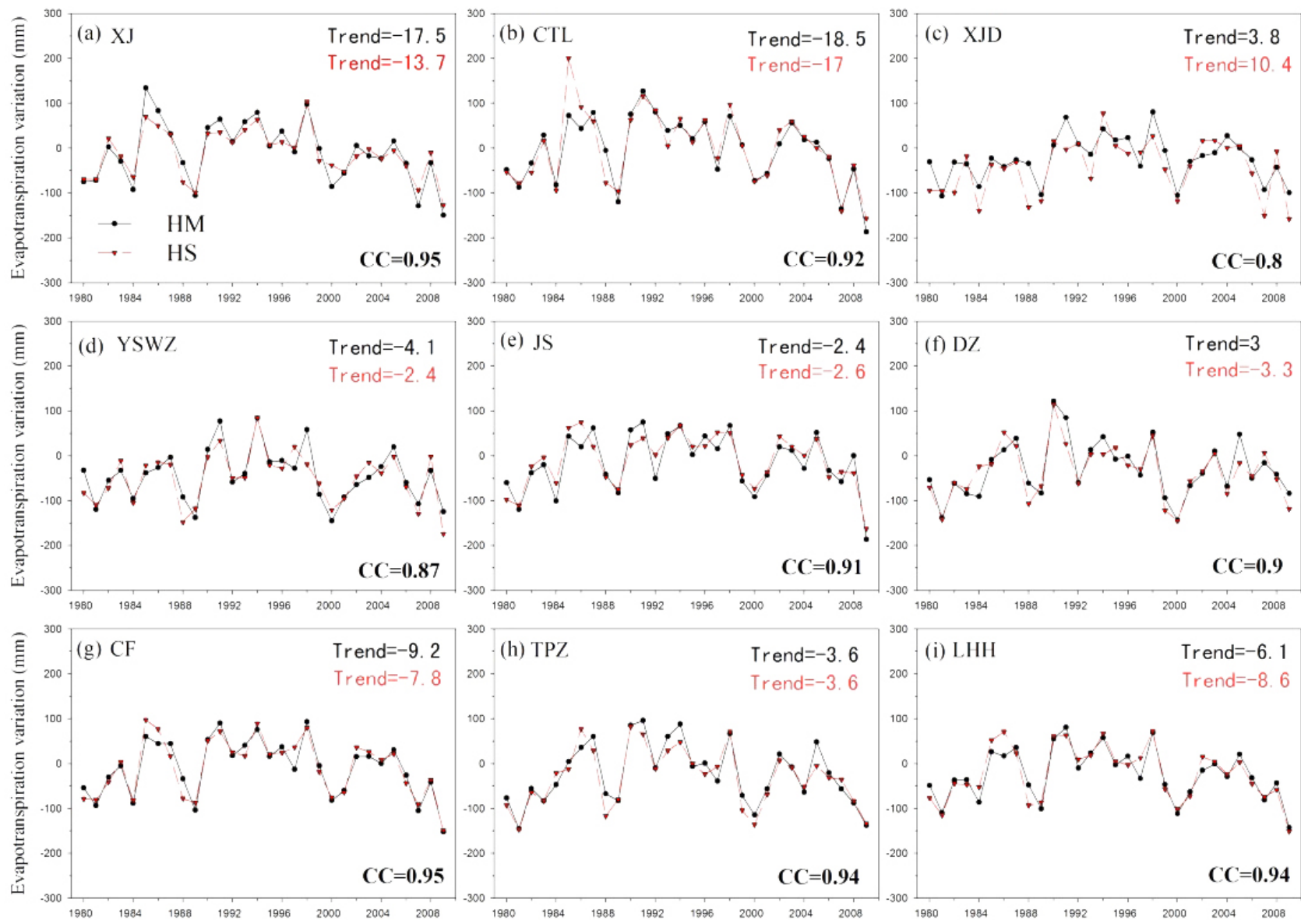

Figure 3. Annual series of climate-induced $\Delta E$ over the whole changed periods. Black solid (red dash) lines denote the $\Delta E$ calculated using the hydrological model simulation method (hydrological sensitivity analysis method). The values in the lower right hand corner of each plot give the correlation coefficient between the two derived $\Delta E$ series.

semi-arid areas than that in semi-humid regions. Considering the six headwater catchments, DZ, YSWZ, XJD and JS catchments located in southern parts generally show similar patterns of $E_{\mathrm{a}}$ variations with TPZ catchment, while that of
CTL and XJ catchments situate in northern parts are analogous to CF catchment.

During the whole changed duration (1980-2009), a general 0-20 mm reduction of $E_{\mathrm{a}}$ is found in most parts of the Laohahe basin with larger reduction in southwest part of the 

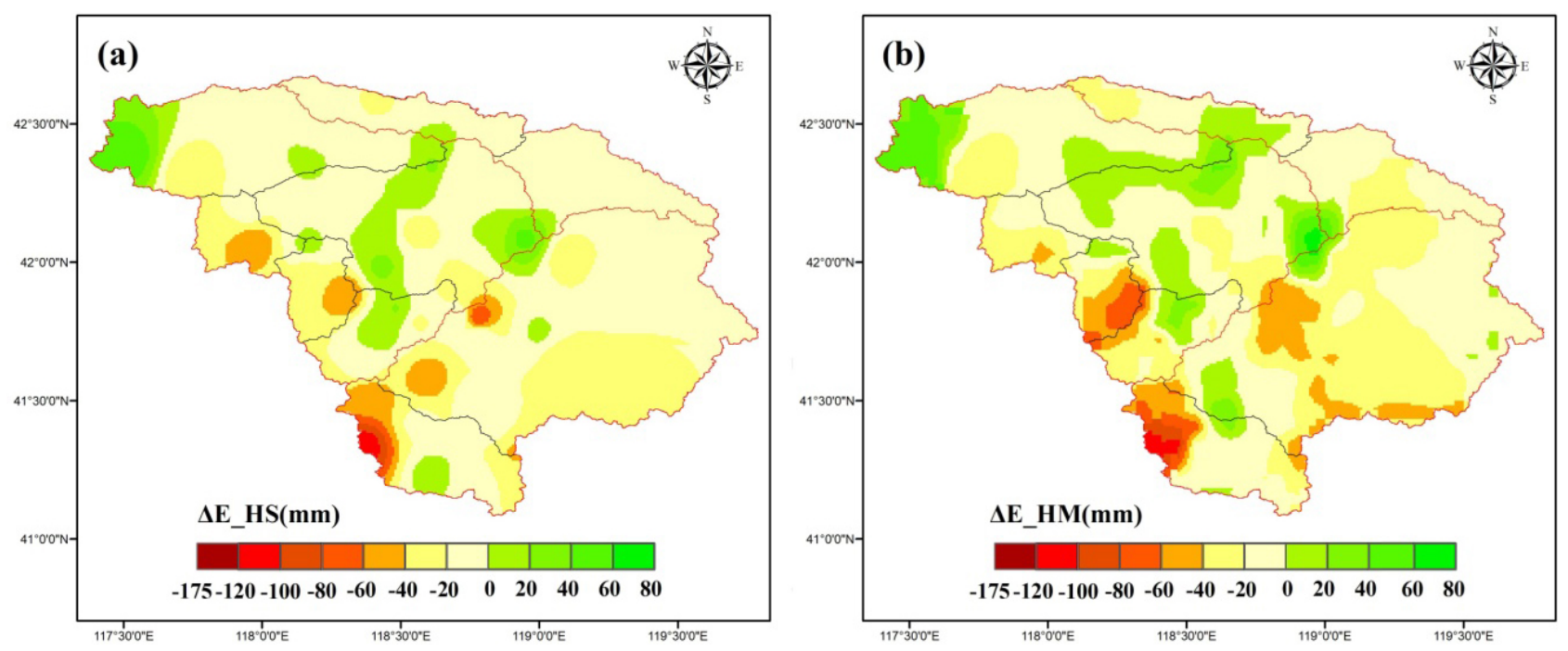

Figure 4. Spatial distribution of $\Delta E$ derived from (a) hydrological sensitivity analysis method (HS) and (b) hydrological model simulation method (HM) during the whole changed period of 1980-2009.

Laohahe basin, in which more than $40 \mathrm{~mm}$ of reduction in $E_{\mathrm{a}}$ is observed (Fig. 4). Additionally, a $0-80 \mathrm{~mm}$ increment of $E_{\mathrm{a}}$ is detected in northern and eastern parts of CF catchment. Some differences in derived spatial distribution of $\Delta E$ from the two methods are also found, especially in TPZ catchment, where hydrological model simulation method seems to present more reduction of $E_{\mathrm{a}}$ than hydrological sensitivity analysis method.

\section{Conclusions}

In this study, we adopt two different methods to evaluate the impact of climate change on $E_{\mathrm{a}}$ within the Laohahe basin. Like other statistical methods, the hydrological sensitivity method treats the studied basin as a black box, and provides the relationship between climate change and hydrological responses without consideration of subsistent hydrological processes. This hypothesis guarantees its effectiveness in general reflecting $E_{\mathrm{a}}$ changes induced by quantitative change of annual precipitation and PET, whereas other effects such as seasonal properties of climatic variables which also influence hydrological responses are not captured. In contrast, the hydrological model simulation method takes its advantages for the elaborate depiction of hydrological processes at a daily step. Overall, at annual scale, the $E_{\mathrm{a}}$ simulated by the two methods is comparable, meanwhile the spatiotemporal variation of $E_{\mathrm{a}}$ derived by each method is similar.

Affected by combined impacts of decreased precipitation and PET, most sub-catchments of this region have suffered a downward trend of annual $E_{\mathrm{a}}$ with a higher descending rate in northern catchments. At decadal scale, $E_{\mathrm{a}}$ presents significant decadal oscillation, and northern catchments generally suffer more changes of $E_{\mathrm{a}}$ than southern catchments, implying that the impact of climatic change on $E_{\mathrm{a}}$ is more intense in semi-arid areas than that in semi-humid regions. For whole changed durations, a general $0-20 \mathrm{~mm}$ reduction of $E_{\mathrm{a}}$ is found in most parts of this region, which is in good agreement with the pattern of precipitation variability.

Acknowledgements. This work was supported by the Special Basic Research Fund for Methodology in Hydrology (Grant no. 2011IM011000) from the Ministry of Sciences and Technology, China, the National Natural Science Foundation of China (Grant no. 41323001), the National Key Technology R\&D Program by Ministry of Sciences and Technology, China (Grant no. 2013BAC10B02), the 111 Project (Grant no. B08048) from the Ministry of Education and State Administration of Foreign Experts Affairs, China, the National Natural Science Foundation of China (Grant no. 41201031) and the Fundamental Research Funds for the Central Universities of China (Grant no. 2014B35814, Grant no. 2014B35914).

\section{References}

Allen, R. G., Pereira, L. S., Raes, D., and Smith, M.: Crop Evapotranspiration: Guidelines for Computing Crop Water Requirements. United Nations Food and Agriculture Organization, Irrigation and Drainage Paper, 56, 1-15, 1998.

Bao, Z., Zhang, J., Liu, J., Wang, G., Yan, X., Wan, X., and Zhang, L.: Sensitivity of hydrological variables to climate change in the Haihe River basin, China, Hydrol. Process., 26, 2294-2306, 2012.

Bartier, P. M. and Keller, C. P.: Multivariate interpolation to incorporate thematic surface data using Inverse Distance Weighting (IDW), Comput. Geosci-uk., 22, 795-799, 1996.

Burn, D. H. and Hesch, N. M.: Trends in evaporation for the Canadian Prairies, J. Hydrol., 336, 61-73, 2007. 
Chattopadhyay, N. and Hulme, M.: Evaporation and potential evapotranspiration in India under conditions of recent and future climate change, Agr. For. Meteorol., 87, 55-73, 1997.

$\mathrm{Fu}, \mathrm{B} .:$ On the calculation of the evaporation from land surface, Sci. Atmos. Sin., 5, 23-31, 1981 (in Chinese).

Huntington, T. G.: Evidence for intensification of the global water cycle: review and synthesis, J. Hydrol., 319, 83-95, 2006.

IPCC: Climate change 2007, the physical science basis. Contribution of working group I to the fourth assessment report of the intergovernmental panel on climate change. Cambridge University Press, Cambridge, 2007.

Koster, R. D. and Suarez, M. J.: A simple framework for examining the interannual variability of land surface moisture fluxes, J. Climate, 12, 1911-1917, 1999.

Lan, C., Zhang, Y., Gao, Y., Hao, Z., and Cairang, L.: The impacts of climate change and land cover/use transition on the hydrology in the upper Yellow River Basin, China, J. Hydrol., 502, 37-52, 2013.

Li, X., Marco, G., Zhai, J., Liu, X., Su, B., and Wang, Y.: Spatiotemporal variation of actual evapotranspiration in the Haihe River Basin of the past 50 years, Quatern. Int., 304, 133-141, 2013.

Liu, B., Xu, M., Henderson, M., and Gong, W.: A spatial analysis of pan evaporation trends in China, 1955-2000, J. Geophys. Res., 109, D15102, doi:10.1029/2004JD004511, 2004.
Liu, Q. and Yang, Z.: Quantitative estimation of the impact of climate change on actual evapotranspiration in the Yellow River Basin, China, J. Hydrol., 395, 226-234, 2010.

Liang, X., Guo, J., and Leung, L. R.: Assessment of the effects of spatial resolutions on daily water flux simulation, J. Hydrol., 298, 287-310, 2004.

Peterson, T. C., Golubev, V. S., and Groisman, P. Y.: Evaporation losing its strength, Nature, 377, 687-688, 1995.

Roderick, M. L. and Farquhar, G. D.: Changes in Australian pan evaporation from 1970 to 2002, Int. J. Climatol., 24, 1077-1090, 2004.

Xie, Z., Yuan, F., Duan, Q., Zheng, J., Liang, M., and Chen, F.: Regional parameter estimation of the VIC land surface model: methodology and application to river basins in China, J. Hydrometeorol., 8, 447-468, 2007.

Hansen, M. C., Defries, R. S., Yownshend, J. R. G., and Sohlberg, R.: Global land cover classification at $1 \mathrm{~km}$ spatial resolution using a classification tree approach, Int. J. Remote. Sens., 21, 13311364, 2000.

Yang, D., Sun, F., Liu, Z., Cong, Z., Ni, G., and Lei, Z.: Analyzing spatial and temporal variability of annual water-energy balance in non-humid regions of China using the Budyko hypothesis, Water Resour. Res., 43, doi:10.1029/2006WR005224, 2007. 